\title{
Population Ageing and the Sustainability of the Spanish National Health System: Some Financial Policy Alternatives
}

\section{Gemma Abio Roig}

Departament de Teoria Econòmica, Facultat de Ciències Econòmiques i Empresarials, Centre d'Anàlisi Econòmica i de les Polítiques Socials (CAEPS), Universitat de Barcelona, Avda. Diagonal 690, 08034, Barcelona, Spain.

E-mail: abio@ub.edu

This paper aims to assess the long-term financial sustainability of the Spanish national health system using Generational Accounting, and investigates the effects of several financial options that governments may use to face the challenges posed by the demographic ageing process. Our results indicate, first, that population ageing will have a substantial impact on future health care expenditure, although the examination of past health expenditure trends seems to indicate that ageing is not the main force behind their growth. Second, we find that the policy proposals put forward to date to solve the financial problems of the health system are clearly insufficient to cope with the levels of expenditure predicted for the future.

The Geneva Papers (2006) 31, 557-580. doi:10.1057/palgrave.gpp.2510104

Keywords: National Health System; Generational Accounting; population ageing; healthcare expenditure

\section{Introduction}

The financial sustainability of the health system is a recurrent issue in the debate on public financial policy. The ageing process currently experienced by most developed countries arguably puts pressure on the financial sustainability of a number of public policy programmes, in particular the pay-as-you-go pension system, the public health system, and the long-term care system. However, while there is abundant evidence of age-related effects in income replacement expenditure, the effect on health utilization and expenditure is less clear-cut.

Assessing the effects of government fiscal performance, and in particular the likely impact of different financial policy reform proposals, requires a long-run perspective in which the economic conditions and the age structure of population may change. Short-run changes in health expenditure may well be sensitive to changes in the political environment ${ }^{1}$ or in the system of economic incentives. ${ }^{2}$

Using the methodology of Generational Accounting, one can assess the extent to which demographic changes challenge a given social policy, assuming that the age

\footnotetext{
${ }^{1}$ Rico and Costa-Font (2005).

${ }^{2}$ López-Casasnovas et al. (2005).
} 
pattern of tax payments and transfer receipts remains constant in relative terms. This method also allows investigation of the effects of policy reform proposals on the public budget. While the sustainability and reform of the public pension system has been widely analysed through this methodology, ${ }^{3}$ only a few Generational Accounting studies have assessed the fiscal sustainability of public health insurance in isolation, ${ }^{4}$ and this is the first such study for Spain. Costa-Font and Patxot ${ }^{5}$ use Generational Accounting to analyse the financial sustainability of long-term care funding options in Spain taking into account the expected demographic transition. Other studies have focused on health expenditure attempting to project its evolution against the background of the ageing process. For example, the European Commission evaluates the impact on public spending on health care expenditure (among other things) for the

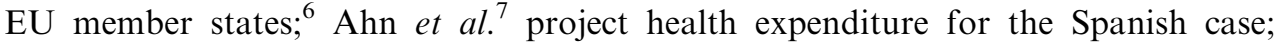
Mahal and Berman ${ }^{8}$ provide a survey for several studies in the U.S. and other countries. More recently, Kotlikoff and Hagist ${ }^{9}$ analyse the growth in real health care benefit levels for a number of OECD countries and examine their long-term fiscal implications.

This paper aims to assess the long-term financial sustainability of the Spanish national health system using Generational Accounting, and investigates the effects of several financial options that governments may use to face the challenges posed by the demographic ageing process. We employ health expenditure data for Spain and, drawing on the Generational Accounting method, project them into the future using a set of microeconomic age profiles of expenditure as well as a long-term demographic forecast. Using this approach, we obtain several indicators that reveal the extent to which the status quo of the health system is sustainable, and the degree of intergenerational redistribution implied by this system. From this, it is also possible to evaluate the impact of different tax policies on the system's financial sustainability. Many experts have proposed the use of excise taxes to finance future health expenditure, and indeed this strategy is on the policy agenda of Spanish politicians. The effect of these and other policies on the public budget balance is stressed and compared with the current fiscal policy. Our results indicate, first, that population ageing will have a substantial impact on future health care expenditure, although the examination of past health expenditure trends seems to indicate that ageing is not the main force behind their growth. ${ }^{10}$ Second, we find that the policy proposals put forward to date to solve the financial problems of the health system are clearly insufficient to cope with the levels of expenditure predicted for the future.

${ }^{3}$ For the case of Spain, see Abío et al. (1999); Patxot and Gil (2000); Bonin et al. (2001); Gil and Patxot (2002).

${ }^{4}$ Within this framework, Hagist et al. (2005) show the unsustainability of the social health insurance systems of France, Germany, Switzerland, and the U.S., given their demographic developments.

${ }^{5}$ Costa-Font and Patxot (2004).

${ }^{6}$ EPC (2001, 2005).

${ }^{7}$ Ahn et al. (2003).

${ }^{8}$ Mahal and Berman (2001).

${ }^{9}$ Kotlikoff and Hagist (2005).

${ }^{10}$ Ibid. 
The paper is organized as follows. In the following section, the Spanish health system is briefly described. The next section explains the Generational Accounting methodology. The following section presents the data and assumptions used, and the penultimate section shows the results. Finally, the last section concludes.

\section{The Spanish health system ${ }^{11}$}

The three main characteristics of the Spanish health system are universal access, tax-based financing, and predominant public provision. The Spanish national health system is characterized by universal coverage. ${ }^{12}$ Coverage guarantees a fairly comprehensive package of benefits to all citizens regardless of personal wealth. If individuals are not covered by the national scheme, this is usually on the grounds of membership in an alternative, employment-linked insurance programme and not on the basis of inability to contribute. About 5 per cent of the population are civil servants and their families, who can choose to be covered either by the national health system or by the private system (financed in any case by public coffers).

The health system is mainly financed through general taxation with the exception of co-payments for drugs not consumed in hospitals. Until 1986, a large part of health expenditure was financed through contributions from both employers and employees. In 1986, this financing system was changed by law, and another one, based on a general taxation scheme, was introduced, which involved the progressive detachment of health care from the social security system. Currently, 98 per cent of total public health care expenditure (excluding civil servants' mutual funds and user co-payments) is funded through general taxation, while the remaining 2 per cent is generated by care provided for patients with other types of coverage. User co-payments to the national health system only apply for pharmaceuticals and some orthopaedic-prosthetic products. In 1998, these were estimated to amount to 1.5 per cent of total public health care expenditure.

In the past, the management of the Spanish national health care system was centralized, but after the end of the dictatorship, responsibility for health care was gradually transferred from the central administration to the regions. The process of decentralization to Autonomous Communities in the field of public health was started in 1978. Catalonia became the first Autonomous Community to take responsibility for health care expenditure in 1981; Andalusia followed in 1984, and by 1994 five more regions had taken charge of health spending. ${ }^{13}$ In 2002, the resources of the system were transferred completely to the 17 autonomous regions, which took charge of their health expenditure. According to this model, each Autonomous Community holds health planning powers as well as the capacity to organize its own health services to the level of decentralization that it considers most appropriate to its needs. This is believed to allow for more effective resource allocation in response to the sociodemographic

\footnotetext{
${ }^{11}$ A more complete description of the Spanish national health system can be found in a report by the European Observatory on Health Care Systems (2000).

12 This includes the immigrant population.

${ }^{13}$ López-Casasnovas et al. (2005).
} 
and cultural characteristics of each community and to achieve a more balanced development of the country's health services. The transfer of resources to the autonomous regions takes into account the size of the population of each region as well as their age. However, decentralization is based on expenditure rather than revenues.

The package of health care benefits in Spain includes:

- Primary health care, which covers general medical and paediatric health care at the doctor's office and the patient's home, as well as programmes for prevention of disease, health promotion, and rehabilitation.

- Specialized health care in the form of outpatient and inpatient care, which covers all medical and surgical specialities in acute care.

- Pharmaceutical benefits, where the user pays 40 per cent of the price of prescription drugs, with the exception of inpatients and specific groups (the retired, the handicapped, invalids, and people who have suffered occupational accidents) for which there are no out-of-pocket payments. There is a range of drugs for chronic diseases for which only 10 per cent of the cost is paid. All users of civil servants' mutual funds pay 30 per cent of pharmaceutical costs.

- Complementary benefits, which include prostheses, orthopaedic products, wheelchairs, health care transportation, complex diets, children's hearing aids, and home-based oxygen therapy.

Excluded benefits are psychoanalysis and hypnosis; spa treatments or rest cures; plastic surgery not related to accidents, disease, or congenital malformation; and dental care (only extractions are included). Note also that the benefit package does not include social and community care, which is significantly underdeveloped in the Spanish public system. Only mental care has been integrated into the national health care system, while long-term care for the elderly and handicapped lags behind that provided in other European countries and is managed by a different organizational structure.

In the period 1998-2003, public health expenditure in Spain grew at an average annual rate of 8.6 per cent. Since 2000, it has risen more rapidly than GDP. ${ }^{14}$ Thus, the share of public health care expenditure has jumped from 5.4 to 5.7 per cent of Spanish GDP. Private health expenditure, on the other hand, accounted for 2.1 per cent of GDP in 2002. Private health care expenditure includes out-of-pocket payments (to the public system and to the private sector, either in the form of user co-payments or fee-for-service) and voluntary insurance. In 1998, total out-of-pocket payments (to the public and private systems) amounted to 16.9 per cent of total health care expenditure. Private voluntary schemes cover some 10 per cent of the population. Some studies suggest that private health insurance increases with income and with the educational level of individuals. ${ }^{15}$

Overall, total (public and private) health expenditure currently accounts for 7.5 per cent of GDP, one of the lowest figures in the EU countries. ${ }^{16}$ In 1997, per capita health

\footnotetext{
${ }^{14}$ Informe de Trabajo del Grupo de Análisis del Gasto Sanitario, MSC (2005).

${ }^{15}$ For example, see Ahn et al. (2003).

${ }^{16}$ For a comparison of EU member states, see EC (2003).
} 
expenditure in Spain represented 75 per cent of the EU average, and the same was true for public health care expenditure. However, life expectancy in Spain was the third highest in the EU in 1996 and was still well above the European average in the late 1990s, especially for women. This is mainly due to the fact that Spain has considerably under-average mortality rates for the most frequent causes of death. This suggests that the low figure for Spanish health expenditure as a percentage of GDP may be due to efficient cost management rather than to limited coverage of the public system.

Several studies ${ }^{17}$ (this one included) suggest that figures of health expenditure will rise in the following decades. One of the reasons for this increase is the ageing process currently experienced by the Spanish population. Despite the fact that long-term care expenditure is not included in the national health system, ${ }^{18}$ spending tends to be concentrated at the later stages of an individual's life, thus increasing costs of health care as the population ages.

\section{Measuring financial sustainability: the Generational Accounting method}

As noted in the introduction, the analysis of the effects of fiscal policy requires a longrun perspective, as well as the inclusion of debts that are implicitly being generated by current policies and will have to be paid by future generations. These implicit debts are not taken into account in conventional measures of the budget balance, which thus omit an important effect of fiscal activity.

These shortcomings of short-term indicators of fiscal policies led to the definition of Generational Accounting by Auerbach et al. ${ }^{19}$ which has become a standard tool to evaluate the long-term impact of government fiscal activity. ${ }^{20}$

The precise theoretical background of Generational Accounting is to be found in general equilibrium models of overlapping generations, the dynamic neoclassical model best suited to approaching population economic issues. Generational Accounting sacrifices some of the general equilibrium aspects of these models in order to gain applicability and focuses strictly on the demographic impact on the public budget. In particular, it maintains the original age and gender incidence of tax payments and transfer receipts, and projects it into the future using demographic forecasts. As a result, the evolution of the government budget in each future year can be extrapolated and thereby the extent to which it meets the intertemporal budget constraint. Hence, while maintaining some of the dynamic developments in the economy, Generational Accounting eliminates the possible response of agents to economic evolution and government policy, which in turns implies constant factor prices.

${ }^{17}$ EPC (2001, 2005); Kotlikoff and Hagist (2005).

${ }^{18}$ Uncertainty remains on whether reforms in the long-term care system will have an effect on the sustainability of the health system.

19 Auerbach et al. (1991, 1994).

${ }^{20}$ For an in-depth introduction to the method of Generational Accounting incorporating new methodological aspects, see Bonin (2001). 


\section{The standard method}

The Generational Accounting method is based on the intertemporal public budget, considered as the aggregate of the present value of current and future primary surpluses associated with present fiscal policy decisions made by the government. The method starts from the notion that, to remain solvent with a given level of historical debt, the present value of future primary surpluses must be sufficiently large to redeem this debt. In technical terms, looking forward from period $t$, the intertemporal financing constraint of the government can be written as

$$
\sum_{i=t}^{\infty} S_{i}(1+r)^{t-i}-B_{t}=0,
$$

where $S_{i}$ stands for the primary surplus in period $i$, which is taken back to period $t$ at a time-invariant annual rate $r$, and $B_{t}$ represents the level of government debt in period $t$.

One may test the sustainability of current fiscal policy by inspecting the corresponding time path of primary surpluses. The difference between base year debt and aggregate primary surpluses represents an - implicit - intertemporal liability of the government, known in Generational Accounting as the sustainability gap. This indicator is usually reported in terms of the present value aggregate of future yearly GDP. It represents the constant share in national product by which the government needs to reduce the primary deficit in each year, in order to achieve fiscal sustainability. In order to calculate this indicator of fiscal policy sustainability, lifetime net tax payments of each generation need to be estimated.

The generational account of a generation is defined as the present value of net tax payments upon death by a representative member of that generation. For living generations - the ones alive in the base year - net tax payments are calculated from the base year on, while for future generations - the ones born after the base year - these payments are calculated during their entire life cycle, from their birth year until death. Hence, assuming that $D$ is the maximum lifespan of an individual, the generational account of a generation born in year $k$ can be expressed as

$$
G A_{k}=\sum_{i=\max \{t, k\}}^{k+D} T_{i, k} \cdot s_{i, k} \cdot(1+r)^{t-i}
$$

for $k=t-D, \ldots, \infty$, where $T_{i, k}$ is the amount of tax payments net of transfer receipts corresponding to the representative individual born in year $k$, and $s_{i, k}$ is the probability that, in period $i$, an individual born in year $k$ survives through the next period. In general, these generational accounts are obtained separately for men and women.

Using the definition of generational accounts, Equation 1 can be rewritten as

$$
B_{t}=\sum_{k=t-D}^{t} G A_{k} \cdot P_{t, k}+\sum_{k=t+1}^{\infty} G A_{k} \cdot P_{k, k},
$$

where $P_{t, k}$ is the size of a generation born in year $k$ and alive at $t$. According to this expression, the public sector debt in year $t$ must be equal to the sum of lifetime net tax payments of living generations from year $t$ on plus lifetime net tax payments of all future generations. 
To estimate the generational accounts of each generation, we use data observed in a cross-section, and produce microeconomic profiles of lifetime net tax payments by age and sex, as described in the next section. Once all generational accounts - for living and future generations - have been estimated, the sustainability gap is obtained from expression 3.

On the other hand, policies which are inconsistent with Equations (1) or (3) imply income redistribution between generations, since the expected level of tax payments and transfer receipts obtained with the considered fiscal policy cannot be maintained indefinitely in the future. Generational Accounting allows us to transform macroeconomic fiscal sustainability measures - that is, the sustainability gap - into measures of intergenerational redistribution of income. To do so, we compare the generational account of a newborn generation in the base year with the generational account of a newborn generation after the base year, assuming that all future generations will be obliged to eliminate the sustainability gap, so that Equation (3) holds. Generational accountants by convention assume that generations born after period $t$ will face a uniform proportional change in their tax payments under the initial fiscal policy to eliminate the sustainability gap. This stylized procedure allows us to illustrate the intertemporal fiscal imbalance as the difference in lifetime net tax burdens of base year and future cohort representatives - both traced over their entire life cycle and hence comparable with each other.

\section{Generational Accounting for the health system}

Before applying the Generational Accounting method to the health system, it is important to state some considerations with respect to the standard methodology outlined above. In particular, only two parts of the overall public budget will be taken into account in our computations: health expenditure and financing sources. In general, Generational Accounting is used to evaluate the sustainability of global fiscal policy and the term $T_{i, k}$ in Equation (2) incorporates all taxes paid and all transfers received - in cash and in kind - from all government institutions. However, when the analysis focuses on a specific programme of the public sector, as is the case of several studies examining the sustainability of the pension system or the present study focusing on the health system, $T_{i, k}$ includes only tax payments used to finance this programme and transfer receipts from this system.

Given that the Spanish national health system is financed through general taxation, at first we only estimate the evolution of health expenditure, as no specific revenues belong to this programme. This is a comprehensive assumption given that the system is proportionally paid overall. In a second step, we introduce the financial side. As there is no clear link between revenue and expenditure, we need to adopt an assumption for the initial deficit and debt levels. Here, we follow other Generational Accounting studies and assume, for simplicity, zero deficit and debt as a benchmark. ${ }^{21}$ In particular, we consider that public health expenditure is financed through a

\footnotetext{
${ }^{21}$ Hence, $B_{t}$ in Equations (1) and (3), which in this case represents the level of initial debt of the health system, is assumed to be zero.
} 
combination of all taxes (direct, indirect, and excise taxes), so that initially the health system has no deficit or surplus. Under the hypothesis that the share of total tax revenue that is earmarked to the public health system remains constant, we evaluate the degree of long-term sustainability of the Spanish national health system. We then perform a series of experiments with different alternative financing sources of the health system and assess their effects on the intertemporal budget equilibrium.

\section{The data and assumptions used}

To develop all the computations required for Generational Accounting, we use the following information: (1) the choice of a base year for the analysis; (2) a demographic projection of the age structure of the population; and (3) projections of tax payments and transfer receipts by age and gender - which, in this case, refer to health expenditure and tax payments to finance them.

The base year chosen for our analysis is 1996 . This year is important given that it is possible to compare estimates with public health care data. This means that our projections start from year 1996, and for reasons of data availability, we have used real data for the period 1996-2001.

Regarding the demographic projections, we use the age structure of the Spanish population in 2001 and project it for 300 years, ${ }^{22}$ based on the hypotheses employed by INE. ${ }^{23}$ These hypotheses are based on the evolution of three important demographic variables: mortality rates, fertility rates, and migration patterns. In fact, INE provides two alternative scenarios. Our results are based on one of these sets of hypotheses, according to which migration flows are those actually observed until year 2003, and from this year on they gradually adjust to the fixed amount of 260,000 annual immigrants in the 2050s, remaining at this value thereafter. With respect to the fertility rate, a linear recovery is assumed from the rate of 1.26 children per woman in 2002 to the rate of 1.53 in 2030, after which it remains constant. Finally, we consider an increase in individual survival probabilities until year 2050, which roughly correspond to an increase in life expectancy at birth of 4.4 and 3.6 years, respectively, for men and women.

Overall, these projections predict that the dependency rate of the old - defined as the number of people over 65 years old divided by the population between 20 and 64 will rise dramatically in the future, rising from around 25 per cent at present to a maximum of 62.4 per cent in year 2050 and decreasing progressively later, stabilizing at 52.5 per cent. ${ }^{24}$

The macroeconomic aggregates concerning public health expenditure and revenue for the period 1996-2001, which are required to obtain the generational accounts, have been compiled from the information given in the government's consolidated

\footnotetext{
${ }^{22}$ Long enough to ensure that the effect of discounting eliminates the values for later years.

23 INE (2005).

${ }^{24}$ The alternative set of hypotheses described in INE (2005), which assumes considerably less immigration and slightly lower gains in longevity, implies a maximum dependency rate of 68.6 per cent in year 2050 and is used in a sensitivity analysis of the results in the section entitled "Sensitivity Scenarios".
} 
Table 1 Composition of the Spanish public sector budget 1996-2001 (millions of Euro)

\begin{tabular}{|c|c|c|c|c|c|c|}
\hline Year & 1996 & 1997 & 1998 & 1999 & 2000 & 2001 \\
\hline Personal income tax & 33,712 & 35,877 & 36,473 & 35,705 & 37,097 & 39,680 \\
\hline Social security contributions & 56,767 & 59,101 & 61,719 & 64,997 & 69,022 & 72,769 \\
\hline Capital income tax & 13,818 & 14,705 & 15,105 & 17,886 & 20,057 & 19,337 \\
\hline Taxes on land property & 3,598 & 3,799 & 4,138 & 4,376 & 4,460 & 4,639 \\
\hline Value added tax & 22,843 & 24,417 & 26,603 & 30,493 & 32,297 & 32,284 \\
\hline Alcohol excise tax & 602 & 652 & 721 & 769 & 747 & 726 \\
\hline Beer excise tax & 150 & 162 & 179 & 168 & 184 & 191 \\
\hline Tobacco excise tax & 3,149 & 3,414 & 3,772 & 3,785 & 4,100 & 4,136 \\
\hline Hydrocarbon oil tax & 7,385 & 8,007 & 8,846 & 9,210 & 9,105 & 8,980 \\
\hline Vehicle taxes & 1,812 & 1,928 & 2,159 & 2,448 & 2,492 & 2,523 \\
\hline Total revenue & 143,834 & 152,062 & 159,715 & 169,836 & 179,560 & 185,264 \\
\hline Inpatient services & 14,285 & 14,517 & 15,044 & 15,583 & 16,212 & 16,631 \\
\hline Outpatient health care & 4,181 & 4,192 & 4,245 & 4,473 & 4,653 & 4,773 \\
\hline Pharmaceuticals & 5,020 & 5,477 & 5,796 & 6,236 & 6,487 & 6,655 \\
\hline Total health expenditure & 23,486 & 24,187 & 25,086 & 26,291 & 27,353 & 28,058 \\
\hline
\end{tabular}

Source: Own elaboration on the basis of IGAE (1998, 1999a, b, 2000a, b, 2001a, b, 2002) and http://www.igae. minhac.es), using the SEC-95 methodology.

accounts. ${ }^{25}$ In particular, we have collected 10 aggregates corresponding to public revenue and one corresponding to public expenditure - that is, health expenditure which has actually been divided into three categories, ${ }^{26}$ as can be observed in Table 1. For all these aggregates, it was possible to construct a microeconomic profile by age and gender of tax payments or transfer receipts, based on several databases.

Generational Accounting uses a three-step procedure to break down the macroeconomic figures of the public budget into profiles of each type of payment and receipt by age and gender. First, a set of microeconomic profiles by age and gender of each type of tax payment and transfer receipt is estimated from the crosssection data observed. These profiles represent the fiscal position of current population with respect to the public sector - or, in this case, with respect to the health system. Second, each one of these profiles is compared to its corresponding macroeconomic aggregate. Then it is assumed that the real profile in the base year is proportional to the observed profile compiled from cross-section databases, and it is recalculated applying a uniform adjustment factor. Finally, as generational accounts have a longitudinal perspective, the cross-section microeconomic profiles are projected into the future by using a constant annual growth rate which accounts for productivity growth in the economy. In this way, the present incidence of fiscal policy by age and gender is maintained indefinitely. However, one of the experiments conducted in this paper considers a different growth rate when projecting health expenditure profiles by

\footnotetext{
${ }^{25} \operatorname{IGAE}(1998,1999 \mathrm{a}, \mathrm{b}, 2000 \mathrm{a}, \mathrm{b}, 2001 \mathrm{a}, \mathrm{b}, 2002)$ and http://www.igae.minhac.es.

26 These can be obtained from MSC (2001).
} 
age and gender. This exercise is required in view of the evidence published in several studies indicating that health expenditure has grown at a faster rate than the average productivity of workers in the economy during the last few decades. ${ }^{27}$

In fact, the critical part of the Generational Accounting method is the production of the microeconomic profiles describing the way in which fiscal legislation assigns individual claims and liabilities against the public sector to specific age groups. While the tax profiles used here are those used in other Generational Accounting studies conducted to date for the overall Spanish budget, we use specific health expenditure profiles designed to analyse the health system, which are therefore more precise than the ones previously used in other studies to analyse the public sector as a whole. In particular, the health expenditure profiles used here are based on the work by Ahn et al. $^{28}$ and by MSC. ${ }^{29}$

In order to produce health expenditure profiles, utilization rates of health care services by age and gender must be explicitly introduced, given that Generational Accounting works with representative individuals. The data available make it possible to calculate the average cost of a given health service for individuals that use it. Then, based on an estimation of the utilization of each service by age and gender groups, this cost is revaluated so that a lower average cost is assigned to all members of a given age and gender for each category of health services. In the following, we briefly describe how these profiles are obtained.

We employ population and health expenditure figures in year 1999. Public health expenditure can be divided into three large components:

1. Inpatient services - including hospitalization expenditure and outpatient major surgery - which constitute 54 per cent of total public health expenditure.

2. Pharmaceutical expenditure, which represents 21.6 per cent of total expenditure; and

3. Outpatient health care - primary and specialized care - which amount to 15.5 per cent of total public health expenditure.

These three categories constitute more than 90 per cent of public health expenditure. The rest is distributed between collective services - public health, administration, training and research - and other expenditure - patient transfers, prostheses and therapeutic equipment, capital expenses and external transfers to private agents.

Inpatient services are classified according to the "diagnosis related groups"(DRGs), which are a set of processes applied to homogeneous groups of patients. The Ministry of Health and Consumers' Affairs provides data on the number of cases of each hospital process by age, as well as the average cost of each DRG. ${ }^{30}$ Then, the profile of inpatient health expenditure is obtained as the sum of the cost of each service in that category multiplied by the number of cases of that service. This procedure is carried out separately for men and women.

\footnotetext{
${ }^{27}$ Kotlikoff and Hagist (2005); EPC (2001, 2005).

${ }^{28}$ Ahn et al. (2003).

${ }^{29}$ MSC (2005).

${ }^{30}$ MSC (2002).
} 


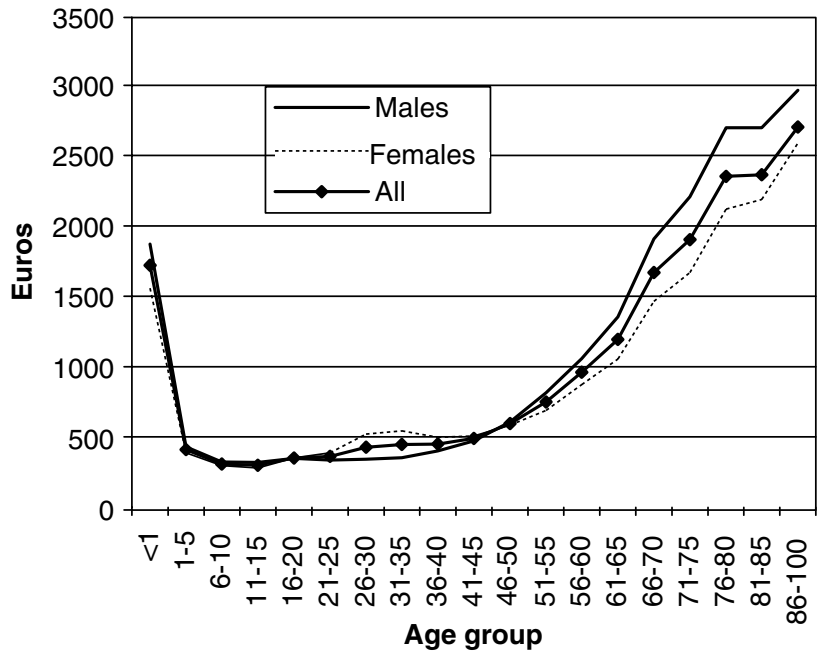

Source: Own elaboration based on the data from Ahn et al. (2003) and MSC (2005).

Figure 1. Health expenditure profiles by age and gender.

In the case of pharmaceuticals, data concerning the pharmaceutical consumption of individuals are available in Digitalis database for year 2001, which provides information on drug consumption as well as its cost structure by age.

In the case of outpatient health care, the National Health Survey ${ }^{31}$ provides data concerning the use of primary and specialized care services. In this case, we assume that the cost of each service is constant and independent of the age and gender of individuals.

Once the three profiles have been obtained, the residual health expenditure - that is, the 8.8 per cent of total public expenditure that does not correspond to any of the three broad categories mentioned above - are uniformly distributed within the total population. Finally, we calculate the average health expenditure of a representative individual of each age and gender as the sum of the health expenditure of the three categories considered corresponding to that age and gender plus the residual health expenditure. The result is shown in Figure 1.

The profile of total health expenditure by age is clearly J-shaped, due to the predominance of the pattern of inpatient services, which also adopts this typical shape of health expenditure. In both cases, expenditure for newborns is high and decreases with age until the age of 15 , it increases only slightly until the age of 45 , and it becomes higher at an increasing rate later. Looking at the differences between men and women, we see that female expenditure is higher at ages between 25 and 40, coinciding with the years of maternity; it stays more or less the same for both genders after this period, and from 50 years old male expenditure remains higher until death. The evolution of 
The Geneva Papers on Risk and Insurance - Issues and Practice

568

Table 2 Long run sustainability indicators for the Spanish national health system

\begin{tabular}{lcc}
\hline Scenario & $\begin{array}{c}\text { Sustainability gap } \\
\text { (\% intertemporal GDP) }\end{array}$ & $\begin{array}{c}\text { Generational account of } \\
\text { base-year newborns }(€)\end{array}$ \\
\hline $\begin{array}{l}\text { Only health expenditure } \\
\text { Baseline: health expenditure financed } \\
\text { through a basket of taxes }\end{array}$ & 6.47 & $-21,600$ \\
Higher growth rate of health expenditure & 1.30 & $-1,000$ \\
Constant mortality & 2.18 & $-3,400$ \\
Population projection with fewer immigrants & 0.91 & 100 \\
\end{tabular}

Source: Author's calculations.

Table 3 Generational accounts for the baseline scenario

\begin{tabular}{lrrr}
\hline Generational account $(€)$ & Males & Females & Average \\
\hline For a base-year newborn (representative of living generations) & 5,100 & $-7,500$ & $-1,000$ \\
For a newborn after the base year (representative of future generations) & 22,400 & 1,800 & 12,400 \\
Absolute difference & 17,400 & 9,200 & 13,400 \\
\hline
\end{tabular}

Source: Author's calculations.

pharmaceuticals, on the other hand, decreases slightly only at the beginning, keeping a relatively stable drug expenditure per capita between birth and 45 years old, and then it increases sharply with age. ${ }^{32}$ The profile of outpatient health care is roughly U-shaped, and higher for females than for males.

Finally, to be able to develop the Generational Accounting exercise, we have chosen a discount rate of 4 per cent - which brings future payments back to the base year and an annual productivity growth rate of 2 per cent. ${ }^{33}$

\section{Results}

The results for the Generational Accounting exercise of the Spanish national health system are presented in Tables 2-5.

\section{Baseline results}

The first column in Table 2 indicates the scenario considered and reflects the type of experiment performed. The other two columns report the sustainability gap and the generational account of newborns in the base year of the analysis. As an illustration, the first experiment considers only public health expenditure, hence

\footnotetext{
32 This profile is in line with those of other empirical studies in Spain that provide evidence of a higher consumption of pharmaceuticals attributable to the elderly (Costa-Font and Puig-Junoy (2005)).

${ }^{33}$ EPC (2001) also uses an interest rate of 4 per cent and a productivity growth rate of 1.75 per cent. However, in a more recent report by the European Commission, both figures are chosen to be lower (see EPC (2005)).
} 
Table 4 Long-run sustainability indicators of the public health system under several financing proposals

\begin{tabular}{lcc}
\hline Scenario & $\begin{array}{c}\text { Sustainability gap (\% } \\
\text { intertemporal GDP) }\end{array}$ & $\begin{array}{c}\text { Generational account } \\
\text { of base-year newborns (€) }\end{array}$ \\
\hline Baseline & 1.30 & $-1,000$ \\
Increase in alcohol excise tax & 1.28 & -900 \\
Increase in alcohol and tobacco excise taxes & 1.25 & -800 \\
Co-payment of 1 euro per visit to the doctor & 1.22 & -700 \\
Increase in excise taxes + co-payment & 1.17 & -400 \\
\hline
\end{tabular}

Source: Author's calculations.

Table 5 Generational accounting results for a capitalization experiment of the national health system

\begin{tabular}{lcc}
\hline Scenario & $\begin{array}{c}\text { Tax increase (\%) for } \\
\text { all generations }\end{array}$ & $\begin{array}{c}\text { Transfer reduction (\%) } \\
\text { for all generations }\end{array}$ \\
\hline Baseline & 25.0 & 20.0 \\
Increase in alcohol and tobacco excise taxes & 23.9 & 19.3 \\
Co-payment of 1 euro per visit to the doctor & 23.1 & 18.8 \\
Increase in excise taxes + co-payment & 22.0 & 18.0 \\
Higher growth rate of Health expenditure & 42.1 & 29.6 \\
Constant mortality & 17.7 & 15.1 \\
Less immigration & 25.1 & 20.1 \\
\hline
\end{tabular}

Source: Author's calculations.

disregarding any revenues to finance it. The results in the first row show the implicit debt accumulated by the health system - under the assumption that its present parameters remain constant - due to population ageing. As can be observed in the table, the sustainability gap in this case accounts for 6.47 per cent of intertemporal GDP. This value implies that, in order to finance health expenditure for present and future generations - considering that each future generation's expenditure increases at the same pace as productivity - the government would have to collect average annual revenues equivalent to 6.47 per cent of GDP for each future year. At the same time, the table shows that the generational account of a newborn in 1996 - that is, a present newborn - is $-21,600$ euros. This means that a representative individual of the generation born in the base year of the analysis obtains a transfer receipt from the public health system that, in present value, amounts to this monetary value.

Figure 2 shows the predicted evolution of health expenditure. As could be expected from the ageing process and from the microeconomic profile shown before, this variable presents a clear demographic dependency. Health expenditure follows a similar evolution to the dependency rate, peaking in around 2050 and decreasing slightly afterwards, to stabilize in the 2070s.

Results for the baseline experiment are shown in the second row of the table. For this scenario, and in the absence of a satisfactory measure for that figure, we assume that the budget for the health system is balanced for the first 6 years - that is, there is no health deficit - while from year 2002 onwards health expenditure is financed 


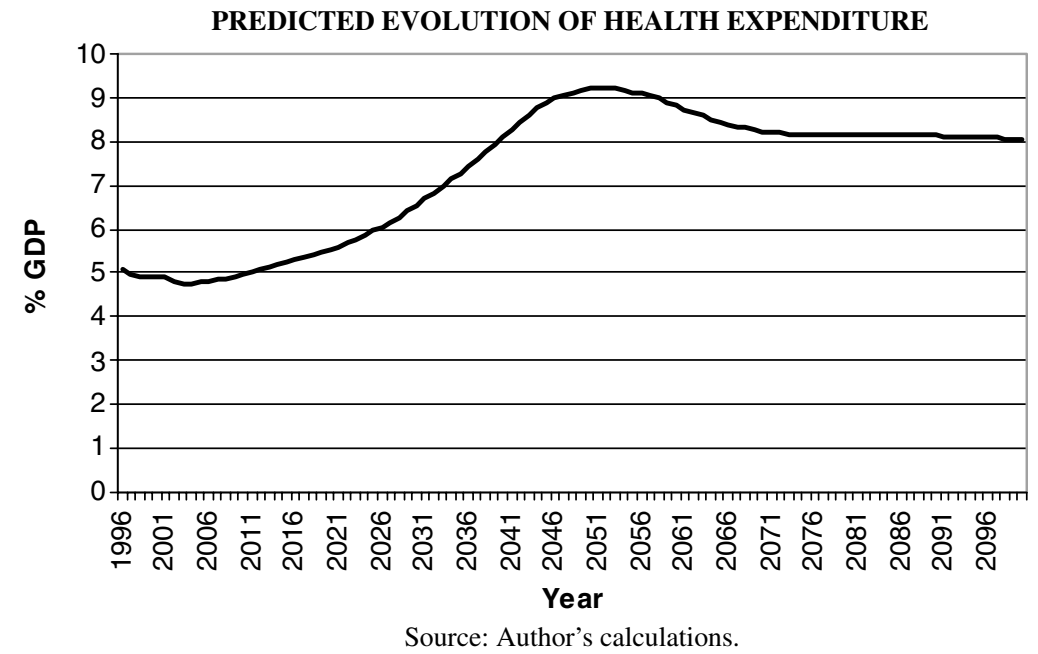

Figure 2. Predicted evolution of health expenditure.

through a basket of taxes including all taxes presented in Table 1. To do so, we assume that the share of tax revenue earmarked to the health system is constant. In this case, the sustainability gap for the baseline amounts to 1.30 per cent of intertemporal GDP. This value indicates that, in order to balance the intertemporal budget constraint of the public health system, taxes should be adjusted each future year to raise, on average, that additional share of GDP.

Table 3 shows the average generational accounts for representative individuals of present and future generations for this scenario, distinguishing between men and women. Compared to the previous results, we can observe that in this case the generational account for present newborns is much smaller in absolute value, as it represents the lifetime transfer received by the representative individual of that generation from the public health system, net of taxes raised to finance this system, according to the assumption explained above. However, the fact that this generational account is negative implies that present newborns receive a net transfer from the public health system, as opposed to future newborns. The generational account for the future newborn is positive - and substantially larger - reflecting a net payment to the system during the individual's lifetime. Therefore, the public health system, with its present expenditure parameters, is redistributing resources between generations in favour of current generations. The fact that the generational accounts for females are substantially lower than for males is a standard result in Generational Accounting, and is due to the great difference in tax payment profiles for each group, since intrafamily transfers are not considered.

\section{Sensitivity scenarios}

It is important to note that the projection of health expenditure employed in this study is based on a set of cross-section expenditure profiles by age that are translated to the 
future considering only the effects of population ageing and the productivity growth rate of the economy. On the one hand, this projection excludes other factors affecting future health expenditure that have been identified as significant by some authors, ${ }^{34}$ such as:

- The increase in the provision of public health services. In fact, a long-lasting debate on the national health system reform revolves around the inclusion of certain services that have been excluded up to now such as, for example, dental services and expanding coverage for mental care.

- Injecting funds to the system to reduce waiting lists for patients and assigning more resources to hospital emergency services.

- The increasing use of new technologies and the fact that the rise in prices of health services and products is above the average inflation rate.

- The increase in demand for health services associated with prosperity.

All these factors suggest that the projections of health expenditure that have been used are likely to be biased downwards, since they have been obtained under the assumption that per capita health expenditure will grow at the same rate as GDP per worker.

On the other hand, when projecting the cross-section health expenditure profiles, we do not take into account the effects of time to death, nor the possibility that the health status of old people will improve with time. For example, Zweifel et al. ${ }^{35}$ argue that, beyond 65 years old, health care expenditure depends on the remaining lifetime (time to death) not on calendar age. Hence, per capita health expenditure is not necessarily affected by the ageing of the population due to an increase in life expectancy. Rather, an increase in the elderly share of population seems to shift the bulk of this expenditure to higher age, leaving per capita health care expenditure unchanged. They conclude that an estimation that does not control for proximity to death will grossly overestimate the effect of population ageing on aggregate health care expenditure. ${ }^{36}$

We developed two sensitivity scenarios to test the relevance of these assumptions. The first one consists of increasing the growth rate of health expenditure above the average productivity growth rate of the economy to account for the non-demographic drivers of health expenditure. The second one consists of assuming constant life expectancy in the population projections, to avoid the bias introduced by the exclusion of time to death. We have also included a third sensitivity experiment that uses alternative demographic hypotheses in the population projections.

Kotlikoff and Hagist ${ }^{37}$ try to measure, for 10 OECD countries, how much of government health care expenditure growth in the period 1970-2002 is due to

\footnotetext{
${ }^{34}$ See Mahal and Berman (2001); Kotlikoff and Hagist (2005); MSC (2005); and EPC (2001, 2005).

${ }^{35}$ Zweifel et al. (1999, 2004).

${ }^{36}$ See also Felder et al. (2000); O'Neill et al. (2000); Serup-Hansen et al. (2002); Stearns and Norton (2004). However, while this effect is clearly evidenced for hospital expenditure, the evidence for pharmaceuticals is less clear-cut. For example, Kildemoes et al. (2006) argue that drug expenditure of elderly decedents is only increasing slightly with proximity to death, so that not accounting for proximity to death does not significantly overestimate the increase in this expenditure. See also Hoover et al. (2002); Yang et al. (2003).

${ }^{37}$ Kotlikoff and Hagist (2005).
} 
demographic change and how much is due to increases in benefit levels. On average, they conclude that three quarters of overall health care expenditure growth can be attributed to growth in benefit levels. In the case of Spain, they find that per capita health expenditure has grown at an annual rate of 5.08 per cent, while benefits have grown at an annual rate of 4.63 per cent (one of the highest in the group), and per capita GDP has had an annual real growth rate of 2.34 per cent. Hence, over the 32-year period, total health care spending grew 2.17 times faster than GDP in Spain, due mostly to the increase in benefit levels. ${ }^{38}$ While in the period considered in their study (1970-2002), population ageing did not play a crucial role, demographic projections for the near future predict that the opposite will be true in the following decades, as shown in Figure 2.

Here, given the difficulty of obtaining a satisfactory estimate of the future growth rate of health expenditure above GDP, as an illustration we have chosen an increase of 0.25 per cent above productivity growth. ${ }^{39}$ The results of this experiment are shown in the third row of Table 2. We can observe that in this case the sustainability gap is substantially larger, and this is also reflected in the other indicator, that is, the generational account of a base-year newborn. In fact, the Generational Accounting results are sensitive to this parameter, as they change notably with a marginal increase in its value. ${ }^{40}$ Hence, we can conclude that the results in this paper will present a substantial downward bias as long as per capita benefit levels by age in the health system continue to increase as fast as they have during the past three decades.

However, one should be careful when interpreting the results for this experiment. Expenditure growth faster than GDP growth raises intertemporal fiscal imbalance and therefore, by the logic of Generational Accounting, one would conclude that it also increases intergenerational redistribution. ${ }^{41}$ While the former conclusion is straightforward, the latter is only valid if excessive expenditure growth is due to inefficient provision of services. If, in contrast, the elevated growth rate is due to increasing demand, improved technologies or better services like shorter waiting lists, individuals receive some kind of return, and they should be willing to bear the extra financial burden imposed by these growth factors.

The fourth row in Table 2 shows the second sensitivity experiment. In the baseline results, the decline of mortality rates present in the population projections, which imply a gain in life expectancy at birth, is assumed not to change the cross-sectional age profile of health expenditure. In other words: while individuals survive longer, they

${ }^{38}$ In MSC (2005), the growth rate of public health expenditure in Spain is decomposed for the period 19992003 into a demographic factor (which explains 21.35 per cent of the annual average growth rate), the change in prices (accounting for 46 per cent), and the increase in the per capita average benefit level of the health system (which explains the remaining 32.65 per cent).

${ }^{39}$ Although this figure seems low, note that it is maintained for 300 years, having a substantial effect.

${ }^{40}$ Hagist et al. (2005) assume a one percentage point higher growth rate of per capita health expenditure than the growth rate of the economy, which is maintained during 40 years. As they acknowledge, the choice of this scenario is completely arbitrary (as in this paper), and the only aim of this exercise is to show how devastating the impact of medical-technical progress can be for fiscal sustainability.

${ }^{41}$ This would be the conclusion when looking at the absolute difference in the generational accounts of base-year and future newborns, which in this case turns out to be 22,500 euros as compared to 13,400 euros in the baseline. 
are assumed to survive longer in bad health. As this is an extreme assumption, we calculate fiscal sustainability under the assumption of constant life expectancy. ${ }^{42}$ Note that this also represents an extreme scenario because we neglect any extra health care expenditure due to increased longevity. ${ }^{43}$ In this way, however, the role of fertility decline is also highlighted, which is anyhow more relevant for the demographic ageing process than increased longevity. The results show that the sustainability gap reduces to $0.91^{44}$ and the generational account of base-year newborns reduces - in absolute value - to 100 euros, even becoming positive. ${ }^{45}$

Finally, the last row in Table 2 presents the results when using an alternative population projection, that is, the second set of hypotheses of demographic evolution in INE. ${ }^{46}$ The main difference between the two demographic scenarios is the number of immigrants, which is substantially lower in this second projection, stabilizing at 100,000 immigrants instead of $260,000 .{ }^{47}$ In addition, life expectancy at birth is slightly lower for both men and women - but especially for women - while fertility rates remain the same in the two sets of hypotheses. Surprisingly, the sustainability gap for this scenario is the same as for the baseline, indicating that the negative effect of the reduced number of immigrants ${ }^{48}$ is compensated by the positive effect of a reduced life expectancy, which seems to have a greater effect on the sustainability of the national health system.

\section{Financing health expenditure}

One of the policy proposals for clearing the deficit of the health system in the various Spanish regions involves raising tobacco and alcohol taxes. The rationale for this measure is that consumption of these products is harmful for health and thus generates more health expenditure. The aim of this policy is not only to obtain additional revenue to finance the public health system but also to discourage the use of tobacco and alcohol. Recently, the Spanish government decided to charge the consumption of these goods by increasing tobacco and alcohol tax rates by 6.3 per cent and 10 per cent,

${ }^{42}$ In particular, we keep life expectancy at birth constant at the level of year 2002, which is the last real figure we can obtain.

${ }^{43}$ An alternative option would be to rely on some ad hoc assumption of how the current age profile shifts to the right when survival probabilities increase.

${ }^{44}$ We can interpret this value as the minimum fiscal imbalance that we could obtain if our profiles took into account the effect of time to death, while the baseline results show the maximum imbalance when this effect is not considered at all.

${ }^{45}$ Hence, present newborns become net contributors to the health system - changing their previous position of net receivers. This is due to the fact that, under this scenario, we eliminate a period - the years of increased life expectancy - where they received high transfers from the national health system as compared to the taxes paid.

${ }^{46}$ INE (2005).

${ }^{47}$ INE (2005) uses this alternative migration hypothesis to resemble the assumptions by Eurostat, which considers much lower net entries of individuals from abroad than the Spanish Statistical National Institute.

${ }^{48}$ We assume that immigrants have the same microeconomic profiles for both taxes and revenues as residents. Hence, the effect of having more immigrants is only reflected in the age structure of the population, which is younger in relative terms. 
respectively. To evaluate the impact of this policy, we carried out two exercises simulating the implementation of these new taxes. On the one hand, we include only the increase in the alcohol tax rate. We assume that the entire additional tax revenue corresponding to the tax rate change is assigned as additional revenue to the health system. The results are shown in Table 4. It can be concluded that this policy has a mild effect on the degree of sustainability of the health system in the long run, reducing the sustainability gap to only 1.28 per cent of intertemporal GDP.

In a second experiment, which is displayed in the third row of Table 4, we include both alcohol and tobacco tax rate increases. In this case, the sustainability gap amounts to 1.25 per cent of intertemporal GDP. Hence, although these measures do have some effect in reducing the present deficit of the system, they are clearly insufficient to resolve the long-term financial problems. ${ }^{49}$ This impression is reinforced by looking at the other indicator presented in the table.

Another proposal put forward in one of the Spanish autonomous regions was to introduce some co-payment for the users of outpatient public health services. Specifically, a token payment of 1 euro was suggested for each medical visit. This proposal caused uproar among both politicians and the general public and was never put into practice. Nevertheless, in the fourth row of Table 4, we have assessed the effects of such a policy proposal on the sustainability of the National Health System. In order to do so, we first developed a set of microeconomic profiles by age and sex concerning medical visits, which were obtained using data from the Spanish National Health Survey in 2003. ${ }^{50}$ These profiles are plotted in Figure 3, and refer to the average number of visits to the doctor in a year. Obviously, the results presented in Table 4 have been obtained by projecting these cross-section profiles into the future taking into account the projected future evolution of population, although we have not incorporated the substitution effect of the co-payment. ${ }^{51}$ The results show that in this case the sustainability gap is reduced to 1.22 per cent, 0.08 per cent less than in the baseline scenario. Note also that the generational account of the present newborns is also reduced, as we assume that the co-payment is introduced in the base year of the analysis. Again, we conclude that this proposal would do very little to solve the financial problems of the health system in the long run.

An additional policy is presented in the last row in Table 4 showing the results for the combined policies of raising the alcohol and tobacco taxes and introducing copayment of 1 euro per visit to the doctor. In this case, the sustainability gap drops to 1.17 per cent of intertemporal GDP. Observe that in this case the generational account

${ }^{49}$ In addition, we should bear in mind that the recent anti-smoking legislation will in fact reduce the collective power of the tobacco tax. Here, we have not taken into account the effects of the new law on the consumption of tobacco, nor that this will also have a positive effect on the expenditure side of the health system. We have not incorporated the substitution effect of the increase in prices either. However, empirical evidence suggests that the demand for tobacco is relatively inelastic. For example, Pinilla (2002) provides a survey of several empirical studies and finds a value of around -0.4 for the Spanish case.

${ }^{50}$ INE (2003).

${ }^{51}$ That is, we have assumed that patterns of health care utilization would remain unvaried. If they were reduced due to the introduction of co-payment, less revenue would be obtained with this policy but health expenditure would also be reduced due to the lower number of visits. 


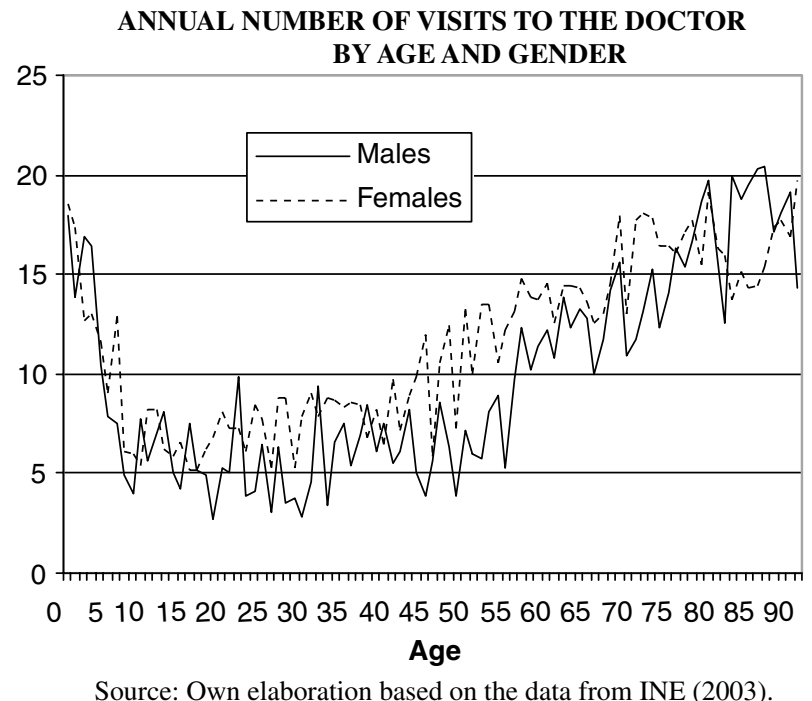

Figure 3. Annual number of visits to the doctor by age and gender.

of present newborns is less than half the generational account in the baseline scenario. This reflects a lower redistribution of resources between generations with this policy, since living generations support a larger part of the burden than in the other scenarios. So far we have seen that neither an increase in excise taxes nor the introduction of co-payment per medical visit, even when combined with the first policy, is sufficient to eliminate the long-term unsustainability of the Spanish national health system due to population ageing. Indeed, the financing of the expected increase in health expenditure has reached the present policy agenda in several countries, together with other ageing-related issues. For example, the unsustainability of the pension system, which is explicitly financed on a pay-as-you-go basis in most developed countries, has been widely discussed, and a number of papers have suggested the implementation of a funded system. We therefore conducted another experiment to explore what kind of policies would solve the financial problems of the health system.

Table 5 contains the results of a capitalization experiment of the health system, which consists of calculating the necessary tax increase and the necessary transfer reduction that should face all generations, including the present ones - that is, the ones that are alive in the base year - in order to eliminate the sustainability gap. ${ }^{52}$ The first column shows the once-and-for-all increase in all taxes paid by all present and future generations required to balance the health system intertemporal budget under the

\footnotetext{
${ }^{52}$ These two indicators have the advantage of not being sensitive to changes in the growth and discount rates.
} 
different scenarios presented before, including the three sensitivity experiments. ${ }^{53}$ In the most favourable case, when alcohol and tobacco taxes are increased and co-payment is introduced, the tax increase drops from 25 per cent in the baseline to 22 per cent. By comparing the generational account for present and future newborns under this policy - which is the same for both - with the ones for the baseline scenario shown in Table 3, we can assess the extent of intergenerational redistribution implied by the present health system. In particular, while in the baseline the present newborn receives a net transfer of 1,000 euros from the national health system and each future newborn is a net payer to the system for an amount of 12,400 euros, under the tax increase policy for all generations, the generational account of all newborns turns out to be 4,200 euros, substantially reducing intergenerational redistribution. The second column shows, for each scenario, the necessary reduction in benefit levels for all present and future generations that would eliminate the implicit debt of the health system. The figures reflect the same conclusion. Notice that transfer cuts do not have to be as large as tax increases. The reason is that the transfers are mostly received by the older generations - which will represent a higher share in the future population structure - while taxes are mainly paid by the working generations, which represent a lower share of the future population. The last three rows reinforce the conclusions obtained before for the sensitivity analysis of the baseline. Note that, to implement these policies and due to the shape of the evolution of health expenditure plotted in Figure 2, a fund should be created in the first years that could accommodate the later deficits arising due to increased demographic dependency. In any case, this analysis is only an illustration and not a potential response to solve the crisis of the health system. In fact, this would generate a similar problem to the often discussed transition to a partially funded pension system, where the active generation needs to contribute twice, although in this case it would be less serious due to the fact that the general taxes used to finance the health system are paid by all individuals, while in the case of the pension system only workers pay social security contributions to finance the income of the retired.

Note also that all the indicators presented in Tables 2, 4 and 5 retain the same ranking of sustainability for the different scenarios. This shows the robustness of the results. Hagist et al. ${ }^{54}$ compute generational accounts and a set of sustainability indicators for the health sectors of France, Germany, Switzerland, and the U.S., including the two indicators presented in Table 5, which they call respectively the "revenue gap" and the "transfer gap". They obtain tax increases that range from 10.8 per cent in France to 45.1 per cent in the U.S., while transfer reductions go from 9.7 per cent to 31.1 per cent in the same two countries. Compared to their results, Spain lies in the middle, in a similar position to Germany, which needs a tax increase of 18.1 per cent or a transfer reduction of 20.4 per cent to balance its health system's intertemporal budget. This result may be surprising, since the fact that the Spanish health care system is entirely financed by general taxes rather than income-related individual contributions suggests that it should be less vulnerable to demographic

\footnotetext{
53 This tax increase is expressed as a proportion of all taxes devoted to financing the health system.

${ }^{54}$ Hagist et al. (2005).
} 
changes compared to other financing schemes like pay-as-you-go. However, this may be partly due to the fact that the Spanish initial tax and transfer quotas are lower. ${ }^{55}$

\section{Conclusion}

This paper deals with the financial sustainability of the Spanish national health system in the long run due to population ageing. The Generational Accounting results obtained indicate the extent to which present patterns of health expenditure by age will challenge public finances if they are maintained for future generations without substantially improving the revenue side of the system. Moreover, several studies point out that the evolution of future health expenditure will be higher for a number of reasons apart from the change in the age structure of the population. According to several authors, population ageing is not the main force driving health care expenditure growth. However, these studies are based on past trends of health expenditure evolution, when population ageing is scarcely present. Our results show that the effect of population ageing on future health expenditure is by no means negligible. In addition, if benefit levels in the health system continue to increase at past rates, the figures obtained are likely to be notably biased downwards.

One of the current proposals to improve the financial sustainability of the system is using alternative instruments to general taxation such as co-payments and raising excise tax rates. The reform proposals to improve the health system's financial situation that have been implemented and discussed up to now are shown to be clearly insufficient in the long run. None of these proposals is able to eliminate or substantially reduce the sustainability gap, as in any case revenues are raised at the same pace as health expenditure is expected to increase. In addition, the evolution of health expenditure across time, heavily dependent on the age structure of population, makes it impossible to finance them on a pay-as-you-go basis.

Our results question the capacity of the health system to obtain sufficient funds by increasing specific taxes and co-payments. It seems then obvious that deeper structural reforms will have to be discussed concerning the system's financial status in order to improve its situation in the long run when the baby-boom generation reaches the last years of their lives. Indeed, this is a relevant issue in the policy agenda of Spanish politicians for the next few years.

Interesting exercises for future research refer to the impact of other financing alternatives, such as the expansion of drug co-payments, which has remained at 40 per cent since the early 1980s. Prescription drugs for pensioners and drugs consumed in hospitals are provided free of charge, and levels of co-payment among the chronically ill are also lower. To date, the Spanish national health system funds 92 per cent of the total pharmaceutical expenditure and the regulation of the Spanish

\footnotetext{
${ }^{55}$ For instance, if we calculate the final tax quota after the required tax increase for all generations to eliminate the sustainability gap, we obtain 6.5 per cent of GDP for Spain, 9.31 per cent for France, 7.56 per cent for Germany, 4.55 per cent for Switzerland, and 10.18 per cent for the U.S., which leaves Spain in a relatively moderate fiscal position when compared with other countries.
} 
drug market has provided very meagre cost-containment incentives for both consumers and providers. 56

The construction of different profiles for the immigrant population is another interesting topic. As in the pension system, the fiscal net contribution of immigrants to the public health system may differ from that of the non-immigrant population (due to lifestyle, other health utilization patterns, and so on). Although the performance of this exercise is heavily dependent on data availability, it seems interesting to analyse the impact of immigrants' patterns of health care expenditure on the long-term sustainability of the health system.

Another issue that merits attention and has not been addressed in the paper is the uncertainty surrounding the potential expansion of the private sector. Private health care in Spain plays a complementary role in the national health system, fulfilling the supplementary demand for quality of care (providing hospital hotel facilities and waiting list avoidance in primary care) and covering some services such as dental care, which is not included in the public system. As income appears to be positively correlated with the probability of purchasing private health insurance, a tax relief in the personal income tax of private health care expenditure would potentially alleviate the financial pressure of the national health system by reducing its utilization.

Finally, a particularly important issue that has not been dealt with in this paper is the role of prevention. Preventive medicine and health promotion, including the undertaking of health education programmes, may have a key role to play in reversing, or at least curbing, the upward trend of health expenditure in the future.

\section{References}

Abio, G., Bonin, H., Gil, J. and Patxot, C. (1999) 'El impacto intergeneracional de la reforma de las pensiones en España: un enfoque de Contabilidad Generacional', Cuadernos Económicos del ICE 65(II): $101-116$.

Ahn, N., Alonso-Meseguer, J. and Herce, J.A. (2003) Gasto sanitario y envejecimiento de la población en España, Documento de Trabajo N. 7, Fundación BBVA.

Auerbach, A.J., Gohkale, J. and Kotlikoff, L. (1991) 'Generational accounting: A meaningful alternative to deficit accounting', Tax Policy and the Economy 5: 55-110.

Auerbach, A.J., Gohkale, J. and Kotlikoff, L. (1994) 'Generational accounting: A meaningful way to evaluate fiscal policy', Journal of Economic Perspectives 8(4): 73-94.

Bonin, H. (2001) Generational Accounting: Theory and Application, Berlin: Springer-Verlag (Population Economics Series).

Bonin, H., Gil, J. and Patxot, C. (2001) 'Beyond the toledo agreement: The intergenerational impact of the Spanish pension reform', Spanish Economic Review 3: 111-130.

Costa-Font, J. and Patxot, C. (2004) 'The intergenerational impact of long-term care financing alternatives in Spain', The Geneva Papers of Risk and Insurance - Issues and Practice 29(4): 599-620.

Costa-Font, J. and Puig-Junoy, J. (2005) 'The Pharmaceutical market regulation in Spain: Is drug cost-containment under question?', Journal of Pharmaceuticals Finance, Economics and Policy 13(4): $33-49$.

EC - European Commission (2003) 'The health status of the European Union - narrowing the health gap'. from http://europa.eu.int/comm/health/ph_overview/previous_programme/mon-itoring/monitoring_ status_en.htm.

\footnotetext{
${ }^{56}$ Costa-Font and Puig-Junoy (2005).
} 
EPC - Economic Policy Committee (2001) 'Budgetary challenges posed by ageing populations: the impact on public spending on pensions, health and long-term care for the elderly and possible indicators of the longterm sustainability of public finances', European Economy, Reports and Studies 04-01.

EPC - Economic Policy Committee (2005) 'The 2005 EPC projections of age-related expenditure: Agreed underlying assumptions and projection methodologies', European Economy. Special Reports 4/2005, from http://europa.eu.int/comm/economy_finance/epc/epc_publications_en.htm.

European Observatory on Health Care Systems (2000) 'Health care systems in transition: Spain', from http://www.euro.who.int/observatory/Hits/TopPage.

Felder, S., Meier, M. and Schmitt, H. (2000) 'Health care expenditure in the last months of life', Journal of Health Economics 19: 679-695.

Gil, J. and Patxot, C. (2002) 'Reformas de la financiación del sistema de pensiones', Revista de Economía Aplicada 10(28): 63-85.

Hagist, C., Klusen, N., Plate, A. and Raffelhuschen, B. (2005) Social Health Insurance - the major driver of unsustainable fiscal policy?, Discussion Paper No. 133/05, Institute for Public Finance, University of Freiburg.

Hoover, D.R., Crystal, S., Kumar, R., Sambamoorthi, U. and Cantor, J.C. (2002) 'Medical expenditures during the last year of life: Findings from the 1992-1996 Medicare current beneficiary survey', Health Services Research 37: 1625-1642.

IGAE - Intervencion General de la Administracion del Estado (1998, 1999b, 2000b, 2001b) Cuentas de las Administraciones Públicas, Madrid.

IGAE - Intervencion General de la Administracion del Estado (1999a, 2000a, 2001a, 2002) Actuación Económica y Financiera de las Administraciones Públicas, Madrid.

INE - Instituto Nacional de Estadistica (1997) Encuesta Nacional de Salud. Resultados. Año 1997, Madrid.

INE - Instituto Nacional de Estadistica (2003) Encuesta Nacional de Salud. Resultados. Año 2003, Madrid.

INE - Instituto Nacional de Estadistica (2005) Proyecciones de población calculadas a partir del Censo de 2001, INEBASE (www.ine.es), Madrid.

Kildemoes, H.W., Christiansen, T., Gyrd-Hansen, D., Kristiansen, I.S. and Andersen, M. (2006) 'The impact of population ageing on future Danish drug expenditure', Health Policy 75(3): 298-311.

Kotlikoff, L.J. and Hagist, C. (2005) Who's going broke? Comparing healthcare costs in ten OECD countries, NBER Working Paper 11833, December 2005.

Lopez-Casasnovas, G., Costa-Font, J. and Planas, I. (2005) 'Diversity and regional inequalities in the Spanish "system of health care services", Health Economics 1(S1): S221-S235.

Mahal, A. and Berman, P. (2001) Health expenditures and the elderly: A survey of issues in forecasting, methods used, and relevance for developing countries, Research Paper No. 01.23 (The global burden of disease 2000 in ageing populations), Harvard Burden of Disease Unit.

MSC - Ministerio de Sanidad Y Consumo (2001) Estadística del Gasto Sanitario Público. Cuentas satélite del gasto sanitario público 1991-1999, Madrid: Centro de Publicaciones.

MSC - Ministerio de Sanidad Y Consumo (2002) Explotación de la Base CMBD. Estadísticas de referencia de la estructura de los sistemas de registro de pacientes (GRD), SNS-1999, Madrid: Centro de Publicaciones.

MSC - Ministerio de Sanidad Y Consumo (2005) 'Informe del Grupo de Trabajo de Análisis del Gasto Sanitario', from http://www.msc.es/estadEstudios/estadisticas/home.htm.

O'Neill, C., Groom, L., Avery, A.J., Boot, D. and Thornhill, K. (2000) 'Age and proximity to death as predictors of GP care costs: Results from a study of nursing home patients', Health Economics 9(8): 733-738.

Patxot, C. and Gil, J. (2000) 'La revisión de la ley de reforma del sistema de la seguridad social: una aproximación de contabilidad generacional', Hacienda Pública Española, Monografías 2000.

Pinilla, J. (2002) 'Análisis comparado del impacto de las políticas impositivas vía precio en el consumo de tabaco', Gaceta Sanitaria 16: 425-435.

Rico, A. and Costa-Font, J. (2005) 'Power rather than path dependency? The dynamics of institutional change under health care federalism', Journal of Health Politics, Policy and Law 30(1-2): $231-252$.

Serup-Hansen, N., Wickstrom, J. and Kristiansen, I.S. (2002) 'Future health care costs - do health care costs during the last year of life matter?', Health Policy 62(2): 161-172. 
Stearns, S.C. and Norton, E.C. (2004) 'Time to include time to death? The future of health care expenditure predictions', Health Economics 13(4): 315-327.

Yang, Z., Norton, E.C. and Stearns, S.C. (2003) 'Longevity and health care expenditures: The real reasons older people spend more', The Journals of Gerontololy, Series B, Psychological Sciences and Social Sciences 58(1): s2-10.

Zweifel, P., Felder, S. and Meiers, M. (1999) 'Ageing of population and health care expenditure: A red herring?', Health Economics 8(6): 485-496.

Zweifel, P., Felder, S. and Werblow, A. (2004) 'Population ageing and health care expenditure: New evidence on the 'red herring", The Geneva Papers of Risk and Insurance - Issues and Practice 29(4): 652-666.

\section{About the Author}

Gemma Abío Roig is a teaching assistant at the economic theory department of the University of Barcelona (Spain). Her major interests are the effects of population ageing on public policy, in particular on the health system and the pension system, and the pay-as-you-go pension system reform. She works with overlapping-generations models and with Generational Accounting. 